\title{
Editorial
}

\section{Catalytic Oxidation of Methane}

\author{
Anil C. Banerjee (1)
}

Citation: Banerjee, A.C. Catalytic Oxidation of Methane. Catalysts 2021, 11,944. https://doi.org/10.3390/ catal11080944

Received: 26 July 2021

Accepted: 2 August 2021

Published: 4 August 2021

Publisher's Note: MDPI stays neutral with regard to jurisdictional claims in published maps and institutional affiliations.

Copyright: (C) 2021 by the author. Licensee MDPI, Basel, Switzerland. This article is an open access article distributed under the terms and conditions of the Creative Commons Attribution (CC BY) license (https:// creativecommons.org/licenses/by/ $4.0 /)$.
Department of Chemistry, Columbus State University, Columbus, GA 31907, USA;

banerjee_anil@columbusstate.edu; Tel.: +1-706-569-3030

\section{Introduction}

Methane (the major component of natural gas) is one of the main energy sources for gas-powered turbines for power generation, and transport vehicles. Methane is 84 times more potent than carbon dioxide as a greenhouse gas and is emitted from power generation, diesel and compressed natural gas engines, gas wells, etc. Catalytic oxidation of methane is an important area for both academic research and industrial applications. The three-way catalytic converters work well at higher temperatures (above $600{ }^{\circ} \mathrm{C}$ ) but are not very effective for lean-burn engines and "idling". Even though a good amount of research has been reported on the catalytic oxidation of methane, the search is still on for the development of low-temperature catalysts [1]. Two recent reviews [2,3] summarized the advances made on development of catalysts, including identification of the active and surface species and the reaction mechanisms during the catalytic combustion of methane. Catalytic oxidation of methane over alumina and ceria supports have been reported to be promising [4-6]. Additionally, particle size, chemical composition, surface species, and metal-support interactions could significantly influence the properties and activities of metal catalysts [7-11].

\section{The Special Issue}

The focus of this Special Issue was on the synthesis, characterization, and activity of catalysts on various supports (alumina, ceria, silica), methane combustion over composite catalysts, reactor design and the combustion characteristics in small-scale systems. Liu et al. [12] reported the development of $\mathrm{Pd} / \mathrm{CeO}_{2}$ catalysts on rice husk silica support for the catalytic methane combustion in the temperature range of $150-500{ }^{\circ} \mathrm{C}$, under methane lean conditions. The incorporation of $\mathrm{Pd}-\mathrm{CeO}_{2}$ into rice husk silica support improved the water-resistance. Khader et al. [13] synthesized palladium/ceria nano-catalysts supported on alumina and prepared via a one-step solution-combustion synthesis (SCS). High-resolution transmission electron microscopy showed bigger Pd particles ( $5 \mathrm{~nm}$ and more) were surrounded by $\mathrm{CeO}_{2}$, resembling a core shell structure. The results indicated that the Pd-SCS nano-catalysts were exceptionally more active and stable than conventional catalysts. A PdO-PdO $/ \gamma \mathrm{Al}_{2} \mathrm{O}_{3}$ catalyst synthesized by a vortex-assisted incipient wetness method exhibited exceptional low-temperature activities, with 90-94\% methane conversion at 300-320 ${ }^{\circ} \mathrm{C}$. X-ray photoelectron spectroscopy established that the active phase, $\mathrm{PdO}_{\mathrm{x}}$ originated from the interaction of $\mathrm{PdO}$ with the alumina support during the calcination process [14]. Banerjee et al. [15] compared the relative efficiencies of $\mathrm{Pd} /$ alumina catalysts prepared by the vortex and incipient wetness methods. The catalyst synthesized by the vortex method produced smaller PdO/PdOx nanoparticles (2-5 nm) and converted 90\% methane at $325^{\circ} \mathrm{C}$. Li et al. [16] reported nitrogen-modified perovskite type composite catalysts prepared by a hydrothermal method for catalytic oxidation of methane. The surface reaction mechanism was investigated using in-situ diffuse reflectance infrared Fourier transform spectroscopy. $\mathrm{LaMnO}_{3}$ catalysts synthesized by sol-gel methods and characterized by a variety of techniques displayed good catalytic activities for hydrocarbon oxidation [17]. Sang et al. [18] designed a novel rotary regenerator-type catalytic combustion reactor and found that the performance of the reactor was more sensitive to the 
increase of velocity and the decrease in methane concentration. Chen et al. investigated the catalytic combustion characteristics of methane-air mixtures in small-scale systems, using computational fluid dynamics simulations and chemical kinetic mechanisms. The results indicated that the distribution of oxidized products depended critically on the feed composition, dimension, temperature, and pressure.

Conflicts of Interest: The author declares no conflict of interest.

\section{References}

1. Farrauto, R.J. Low-temperature oxidation of methane. Science 2012, 337, 659-660. [CrossRef] [PubMed]

2. Monai, M.; Montini, T.; Gorte, R.J.; Fornasiero, P. Catalytic Oxidation of Methane: Pd and Beyond. Eur. J. Inorg. Chem. 2018, 2018, 2884-2893. [CrossRef]

3. Chen, J.; Arandiyan, H.; Gao, X.; Li, J. Recent Advances in Catalysts for Methane Combustion. Catal. Surv. Asia 2015, 19, 140-171. [CrossRef]

4. Cargnello, M.; Jaén, J.J.D.; Garrido, J.C.H.; Bakhmutsky, K.; Montini, T.; Gámez, J.J.C.; Gorte, R.J.; Fornasiero, P. Exceptional Activity for Methane Combustion over Modular Pd@CeO2 Subunits on Functionalized $\mathrm{Al}_{2} \mathrm{O}_{3}$. Science 2012, 337, 713-718. [CrossRef] [PubMed]

5. Fertal, D.R.; Bukhovko, M.P.; Ding, Y.; Billor, M.Z.; Banerjee, A.C. Particle size and Pdo-support interactions in pdo/ceo2- $\gamma$ $\mathrm{Al} 2 \mathrm{O} 3$ catalysts and effect on methane combustion. Catalysts 2020, 10,976. [CrossRef]

6. Willis, J.J.; Gallo, A.; Sokaras, D.; Aljama, H.; Nowak, S.H.; Goodman, E.D.; Wu, L.; Tassone, C.J.; Jaramillo, T.F.; Abild-Pedersen, F.; et al. Systematic Structure-Property Relationship Studies in Palladium-Catalyzed Methane Complete Combustion. ACS Catal. 2017, 7, 7810-7821. [CrossRef]

7. Piccolo, L. Restructuring effects of the chemical environment in metal nanocatalysis and single-atom catalysis. Catal. Today 2020, 373, 80-97. [CrossRef]

8. Liu, L.; Corma, A. Metal Catalysts for Heterogeneous Catalysis: From Single Atoms to Nanoclusters and Nanoparticles. Chem. Rev. 2018, 118, 4981-5079. [CrossRef] [PubMed]

9. Ahmadi, M.; Mistry, H.; Roldan Cuenya, B. Tailoring the Catalytic Properties of Metal Nanoparticles via Support Interactions. J. Phys. Chem. Lett. 2016, 7, 3519-3533. [CrossRef] [PubMed]

10. Murata, K.; Mahara, Y.; Ohyama, J.; Yamamoto, Y.; Arai, S.; Satsuma, A. The Metal-Support Interaction Concerning the Particle Size Effect of Pd/Al2O3 on Methane Combustion. Angew. Chem. 2017, 56, 15993-15997. [CrossRef] [PubMed]

11. Chen, J.; Zhong, J.; Wu, Y.; Hu, W.; Qu, P.; Xiao, X.; Zhang, G.; Liu, X.; Jiao, Y.; Zhong, L.; et al. Particle Size Effects in Stoichiometric Methane Combustion: Structure-Activity Relationship of Pd Catalyst Supported on Gamma-Alumina. ACS Catal. 2020, 10, 10339-10349. [CrossRef]

12. Liu, D.; Seeburg, D.; Kreft, S.; Bindig, R.; Hartmann, I.; Schneider, D.; Enke, D.; Wohlrab, S. Rice Husk Derived Porous Silica as Support for $\mathrm{Pd}$ and $\mathrm{CeO}_{2}$ for Low Temperature Catalytic Methane Combustion. Catalysts 2019, 9, 26. [CrossRef]

13. Khader, M.M.; Al-Marri, M.J.; Ali, S.; Abdelmoneim, A.G. Active and Stable Methane Oxidation Nano-Catalyst with HighlyIonized Palladium Species Prepared by Solution Combustion Synthesis. Catalysts 2018, 8, 66. [CrossRef]

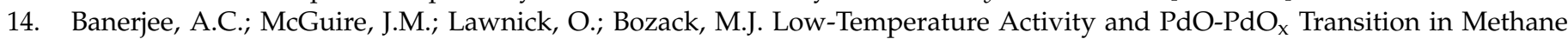
Combustion by a PdO-PdO $\mathrm{P}_{\mathrm{x}} / \gamma-\mathrm{Al}_{2} \mathrm{O}_{3}$ Catalyst. Catalysts 2018, 8, 266. [CrossRef]

15. Banerjee, A.C.; Golub, K.W.; Hakim, M.A.; Billor, M.Z. Comparative Study of the Characteristics and Activities of $\mathrm{Pd} / \gamma-\mathrm{Al}_{2} \mathrm{O}_{3}$ Catalysts Prepared by Vortex and Incipient Wetness Methods. Catalysts 2019, 9, 336. [CrossRef]

16. Li, M.; Gui, P.; Zheng, L.; Li, J.; Xue, G.; Liang, J. Active Component Migration and Catalytic Properties of Nitrogen Modified Composite Catalytic Materials. Catalysts 2018, 8, 125. [CrossRef]

17. Sihaib, Z.; Puleo, F.; Pantaleo, G.; La Parola, V.; Valverde, J.L.; Gil, S.; Liotta, L.F.; Giroir-Fendler, A. The Effect of Citric Acid Concentration on the Properties of $\mathrm{LaMnO}_{3}$ as a Catalyst for Hydrocarbon Oxidation. Catalysts 2019, 9, 226. [CrossRef]

18. Sang, Z.; Bo, Z.; Lv, X.; Weng, Y. Numerical Investigations of the Influencing Factors on a Rotary Regenerator-Type Catalytic Combustion Reactor. Catalysts 2018, 8, 173. [CrossRef] 